\title{
Why Do Firms in Developing Countries Have Low Productivity?
}

\author{
By Nicholas Bloom, Aprajit Mahajan, David McKenzie, and John Roberts ${ }^{\text {* }}$
}

The productivity of firms in developing countries appears to be extremely low. Table 1 reports GDP per capita and average firm-level sales per employee in manufacturing - commonly known as labor revenue productivity-across a sample of countries from a new international firm database (ORBIS). While there are some data comparability issues, the broad message seems clear: developing-country firms have lower levels of labor productivity.

Prior work, such as that summarized in James Tybout (2000) and World Bank (2004), has highlighted a set of issues around infrastructure, informality, regulations, trade policies, and human capital that reduce the productivity of firms in developing countries. In this short article we want to focus instead on three other areas which recent research has emphasized: management practices, financial constraints, and the delegation of decision making.

To summarize: we find evidence that firms in developing countries are often badly managed, which substantially reduces their productivity. This appears particularly important in larger firms (100+ employees), which are operationally complex so that effective coordination and motivation require formalized management practices. We also find that financial constraints are a binding factor for growth, notably in smaller firms. In larger firms, which often appear to have already overcome financing constraints, another growth constraint arises in the inability of firms to successfully decentralize decision making. In developing countries owners tend to make almost all major management

\footnotetext{
*Bloom: Stanford University, 578 Serra Mall, Stanford, CA 94350 (e-mail: nbloom@stanford.edu); Mahajan: Stanford University, 578 Serra Mall, Stanford, CA 94350 (e-mail: amahajan@stanford.edu); McKenzie: Development Research Group, World Bank, 1818 H Street N.W., Washington DC 20433 (e-mail: dmckenzie@worldbank.org); Roberts: Stanford University, Graduate School of Business, 518 Memorial Way, Stanford, CA 94350 (e-mail: Roberts_john@gsb. stanford.edu). We would like to thank Edison Yu for fantastic research assistance and Ben Moll for great comments.
}

Table 1-Average Firm Labor Revenue Productivity ACROSS COUNTRIES

\begin{tabular}{lcc}
\hline \hline Country & $\begin{array}{c}\text { GDP per capita, } \\
\text { dollars }\end{array}$ & $\begin{array}{c}\text { Sales per } \\
\text { employee, dollars }\end{array}$ \\
\hline US & 42,736 & 433,884 \\
UK & 37,886 & 457,674 \\
Japan & 35,699 & 428,336 \\
France & 35,100 & 393,024 \\
Germany & 33,838 & 379,341 \\
Greece & 22,410 & 320,859 \\
Poland & 7,967 & 178,525 \\
Brazil & 4,787 & 144,831 \\
Colombia & 3,170 & 150,198 \\
Ecuador & 2,814 & 71,263 \\
Morocco & 1,952 & 105,271 \\
China & 1,761 & 66,885 \\
Indonesia & 1,249 & 80,203 \\
Philippines & 1,090 & 102,975 \\
India & 741 & 120,656 \\
\hline
\end{tabular}

Notes: GDP per capita from the IMF 2005 in \$PPP. Sales/ Employee in current dollars, across all firms in the ORBIS database, using the most recent accounts. Full underlying data available at: http://www.stanford.edu/ nbloom/T1.zip.

decisions because of fears of expropriation by their managers. But, because the owners' time is limited, they have the capacity to make decisions for firms only up to a certain size. Thus, without delegating decision-making these firms find that growth becomes unprofitable, or even impossible, because decisions are constrained by their owners' time. This suggests that the results of Eric Bartelsman, John Haltiwanger and Stefano Scarpetta (2009) and Chang-Tai Hsieh and Peter Klenow (2009) - that productive firms in developing countries like India and China do not expand as rapidly_-due to a mix of financial factors (particularly for smaller firms) and organizational factors (particularly for larger firms).

\section{Management Practices}

There has long been a suspicion that poor management practices have held back the productivity of firms in developing countries. Indeed, even among industrialized countries, 
management may affect productivity: Alfred Chandler (1994) suggests that the United States and Germany pulled ahead of the rest of Europe in the early 1900s due to superior management, while Toyota's management system is credited with its productivity advantage over US auto firms. However, there is skepticism in the economics profession as to whether management matters, or whether better management just occurs in firms that are more productive due to other unobservable factors.

The first barrier to comparing management practices across countries has been measurement. However, recent work by Bloom and John Van Reenen (2007 and 2010) has started collecting data on management practices in medium and large (100 to 5,000 employee) manufacturing firms across countries. These surveys use double-blind techniques to score firms on: (i) monitoring practices (the collection and processing of production information), (ii) target-setting practices (the ability to set coherent, binding short- and long-run targets), and (iii) incentive practices (merit-based pay, promotion, hiring and firing). They find that developing countries like Brazil, China and India have significantly lower average management scores than firms in the United States, Japan and Western Europe. In fact, the whole distribution of practices across firms in developing countries is typically stochastically dominated by the distribution in rich countries.

The lower level of average management practices in developing countries occurs because of a persistent, thick tail of badly managed firms. In the United States badly managed firms appear to improve or exit, while in developing countries they do not. The evidence surveyed in Bloom, Raffaella Sadun, and Van Reenen (forthcoming) suggests a key factor behind this is low levels of competition and high levels of family ownership in developing countries, which leads to the survival of many badly-run firms.

In order to understand whether better management causally affects performance, we are running a randomized experiment in India (Bloom, Benjamin Eifert, Mahajan, McKenzie, and Roberts 2010), henceforth BEMMR. The research takes a group of large Indian textile plants and randomly allocates each to a treatment or a control group. The treatment plants get five months of extensive consulting to help them introduce a common set of basic management practices around quality control, inventory control and operational efficiency. The control firms get one month of light consulting, which is needed to generate and collect performance data.

The early results have been startling-when these firms adopted these basic management practices they obtained massive improvements in productivity and profitability. For example, most firms previously had no quality measurement systems, so the same production defects would persist for long periods of time. Introducing systems to measure quality defects and analyze the data enabled firms to correct the causes of defects quickly, reducing average defects levels by over 50 percent in the first three months alone. Because almost one fifth of the labor force in these firms was involved in repairing quality defects, this led to huge improvements in labor productivity. Our sense is that if these firms fully adopted the modern lean manufacturing and human resource management practices that are in common use in developed countries, they could potentially increase their productivity by up to several hundred percent.

The obvious next question is why had these practices not been introduced earlier? The initial evidence in BEMMR suggests that one major reason is the firms were simply not aware of many modern manufacturing practices. [1] Another reason appears to be that middle and senior managers lack the autonomy and the incentives to improve management practices. In ongoing work we are monitoring the extent to which the treatment firms are able to spread these types of modern management practices from their treatment plants to other plants within the same firm once they know these methods. We are also investigating whether the introduction of performance related pay for managers motivates them to introduce modern management practices.

\footnotetext{
${ }^{1}$ Information also appears important in other development contexts, for example, in explaining why Ghanaian farmers do not use modern farming methods (Tim Conley and Chris Udry forthcoming), and why microenterprises in Peru do not use basic accounting and marketing practices (Dean Karlan and Martin Valdivia 2009).
} 


\section{Delegation}

Another striking fact about firms in developing countries is the marked lack of delegation of decision making from owners to senior managers. The top executive, who is typically also the owner of the firm, tends to make almost all the major decisions on investment, employment, procurement and production. In the BEMMR textile firms, every purchase order typically required the sign-off from the owner, even orders for a $\$ 25$ spare part. In contrast, in a cross-country survey of 6,000 medium sized (100 to 5,000 employee) manufacturing firms Bloom, Sadun and Van Reenen (henceforth BSVR) (forthcoming) found plant managers in the US, Europe and Japan can, on average, make investments of about $\$ 50,000$ without explicit authorization from higher levels. As in BEMMR, BSVR also found very little delegation in developing countries like Brazil, China and India, where decisions on employment, capital investment, new products and pricing were typically made only by the owner CEOs.

The BSVR results also suggest a number of reasons for this lack of decentralization in developing countries. One is poor rule of law, as the owners typically fear that managers will steal from them if given greater autonomy, and they will not be able to punish them without an effective legal system. A second reason is poor general management practices. Since firms in developing countries do not have good data systems for measuring outputs, inputs, inventories, and spares, the opportunity for undetected theft is much greater. A third reason is the promotion opportunities for managers in developing countries are limited because the top managerial layers in almost all firms are filled by family members of the owner because outsiders are not trusted. This reduces the incentives for midlevel managers to develop their decision-making skills, or for firm owners to train them to make important decisions. The impact on productivity of developing-country firms of this limited decentralization is twofold:

The Lack of Delegation Impedes Reallocation.-If the owners are unable to delegate decision making, firm growth is restricted by the supply of their time. As firms grow larger they generate a need for more decisions over production, sales and finance. Unless the owners are prepared to increase their supply of time, the quality of decision making will decline and, with it, the possibility for profitable growth. In the firms surveyed in BEMMR, growth of the well-managed firms was explicitly constrained by the availability of the owners' time. The owners were extremely busy managing their current production plants because they never delegated, so that they were unable to undertake the management of additional plants. Revealingly, the number of brothers and sons of the firm's owner is an excellent predictor of firm size in the BEMMR sample, because the owners trust relatives and so will delegate decisions to them (unlike a professional manager). The firms in which the owners had multiple brothers and sons had set up multiple production plants, even when badly managed, while the best managed firm in the sample was run by an owner with no brothers or sons and so the firm operated only a single large production plant.

\section{Limited Delegation Impedes Within-Firm} Productivity.-Limited delegation also affected the BEMMR firms in India by introducing inefficiency into the decision-making process. For example, at several factories we found key pieces of equipment - like textile lifts and trolleys - had stopped working, leading to substantial drops in productivity. The plant managers did not have the authority to order parts to repair this equipment, and since the owners were often traveling on business, these problems would persist. In firms in developed countries senior management could easily make substantial expenditures to repair basic equipment without senior authorization, so equipment breakdowns are less damaging for productivity. This illustrates one problem with hierarchical decision making, which is the large time delays in processing information, leading to losses from unfixed problems.

\section{Finance}

In surveys, many firms report access to finance or the cost of finance as a major obstacle to their growth. Although the variation across countries is large, firms in developed countries are less likely to report finance to be a constraint than firms in developing countries, and larger firms are less likely to report facing financing constraints than smaller firms. Moreover, Thorsten Beck, Asli Demirgüç-Kunt, 
and Vojislav Maksimovic (2005) show that there is an association in cross-country data between identifying finance as a constraint and having slow output growth.

Of course this association may just reflect the financing system optimally allocating less money to less successful firms with poorer growth prospects. However, several recent studies go further and show a causal relationship between access to finance and profits or sales growth. Suresh De Mel, McKenzie, and Christopher Woodruff (2008) conducted a randomized experiment that gave grants of $\$ 100$ $\$ 200$ to microenterprises in Sri Lanka. They found this increased capital stock and firm profits, with an implied real return to capital of five percent per month. Abhijit Banerjee and Esther Duflo (2008) used a policy change in India to examine the impact of access to credit on medium-sized firms in India (with $\$ 140,000$ $\$ 640,000$ in capital stock). They found that firms that received extra credit as a result of a directed lending policy (which they argue were the most productive firms) had an annual return on these loans of close to 90 percent.

In contrast, financing may not be such a direct constraint on productivity and growth for large firms - the fact that they have been able to get large in the first place itself reveals more access to internal or external capital than at smaller firms. Among the firms in the BEMMR field experiment, which had a median of $\$ 13.3$ million of capital assets, none considered finance to be a severe constraint. These firms regularly made large investments in physical equipment of $\$ 1$ million or more.

Nevertheless, financing constraints may still be important in allowing the bad management and organizational practices described above to persist. There are at least two channels through which this might happen. First, while firms might easily obtain financing for physical capital investments, it might be harder to borrow to hire consultants or to finance business education for managers. One reason for this is that physical capital is collateral, which can be seized in case of default, whereas better management and organizational practices cannot. However, just as important might be the general lack of awareness of the importance of these factors in increasing productivity. Banks ask for cash flow forecasts of new investments in deciding whether or not to approve a given loan request, and given that the BEMMR firms themselves did not ex ante recognize the value of improving management, it seems reasonable to believe that even if an astute owner did see the benefit of improving management practices, a bank would look askance at requests for financing based on the returns to better management from hiring a consultant.

Second, even if financing is not such a constraint for existing (large) firms, financing obstacles are likely to limit the extent to which individuals with better managerial talent, but low capital, can start and grow enterprises to compete with badly managed firms. Coupled with the inability of better managed firms to delegate and thus to grow beyond a certain size, this lack of competition from new entrants who are short of financing will keep productivity low by limiting the degree to which reallocation occurs from poorly managed to better managed firms.

\section{REFERENCES}

Banerjee, Abhijit V., and Esther Duflo. 2008. "Do Firms Want to Borrow More? Testing Credit Constraints Using a Directed Lending Program." MIT Department of Economics Working Paper 02-25.

Bartelsman, Eric J., John C. Haltiwanger, and Stefano Scarpetta. 2009. "Cross-Country Differences in Productivity: The Role of Allocation and Selection." National Bureau of Economic Research Working Paper 15490.

- Beck, Thorsten, Asli Demirgüç-Kunt, and Vojislav Maksimovic. 2005. "Financial and Legal Constraints to Growth: Does Firm Size Matter?" Journal of Finance, 60(1): 137-77.

-Bloom, Nicholas, and John Van Reenen. 2007. "Measuring and Explaining Management Practices across Firms and Countries." Quarterly Journal of Economics, 122(4): 1351-408.

-Bloom, Nicholas, and John Van Reenen. 2010. "Why Do Management Practices Differ across Firms and Countries?" Journal of Economic Perspectives, 24(1): 203-24.

Bloom, Nicholas, Raffaella Sadun, and John Van Reenen. 2009. "The Organization of Firms across Countries." National Bureau of Economic Research Working Paper 15129.

Bloom, Nicholas, Raffaella Sadun, and John Van Reenen. Forthcoming. "Recent Advances in 
the Empirics of Organizational Economics." Annual Review of Economics.

-Conley, Timothy G., and Christopher R. Udry. 2010. "Learning About a New Technology: Pineapple in Ghana." American Economic Review, 100(1): 35-69.

-De Mel, Suresh, David McKenzie, and Christopher Woodruff. 2008. "Returns to Capital in Microenterprises: Evidence from a Field Experiment." Quarterly Journal of Economics, 123(4): 1329-72.

-Hsieh, Chang-Tai, and Peter J. Klenow. 2009. "Misallocation and Manufacturing TFP in China and India." Quarterly Journal of Economics, 124(4): 1403-48.
Karlan, Dean, and Martin Valdivia. 2009. "Teaching Entrepreneurship: Impact of Business Training on Microfinance Clients and Institutions." Unpublished.

Tybout, James R. 2000. "Manufacturing Firms in Developing Countries: How Well Do They Do, and Why?" Journal of Economic Literature, 38(1): 11-44.

Womack, James P., Daniel T. Jones, and Daniel Roos. 1990. The Machine that Changed the World. New York: Rawson Associates.

World Bank. 2004. World Development Report 2005: A Better Investment Climate for Everyone. World Bank. Washington, DC, September. 